\title{
BUSCANDO PRODUÇÕES ACADÊMICAS ACERCA DO ENSINO DE BOTÂNICA: UMA PESQUISA DE LEVANTAMENTO BIBLIOGRÁFICO
}

\section{SEARCHING FOR ACADEMIC PRODUCTIONS FROM BOTANIC TEACHINGS: A BIBLIOGRAPHICAL RESEARCH}

\author{
Cássia Luã Pires de Souza \\ Universidade Federal do Rio Grande do Sul, Departamento de Bioquímica, Programa de Pós- \\ Graduação Educação em Ciências - Química da Vida e Saúde, cassia-lua@hotmail.com
}

\section{Rosane Nunes Garcia}

Universidade Federal do Rio Grande do Sul, Programa de Pós-Graduação Educação em Ciências - Química da Vida e Saúde; Colégio Aplicação, UFRGS, rosane.garcia@ufrgs.br

\section{Resumo}

Este trabalho buscou investigar e analisar o quanto a comunidade acadêmica desenvolve produções relacionadas a um Ensino de Botânica diferenciado sobretudo com o enfoque Ciência-Tecnologia-Sociedade (CTS) e que favoreça a Alfabetização Científica dos estudantes. Realizou-se um levantamento bibliográfico sobre produções acadêmicas de Ensino de Botânica em uma base de dados no período entre 2012-2017. Verificou-se que há uma preocupação nas produções em melhorar o ensino de botânica, principalmente na Educação Básica, mas as produções ainda são poucas, especialmente as baseadas no ensino CTS. A maior parte das produções acadêmicas concentraram-se no Ensino Médio; as classificadas como pesquisa foram a maioria e predominaram em 2015. Em relação ao tipo de produção, os artigos completos publicados em revistas indexadas foram maioria. Seria interessante que a comunidade acadêmica investisse mais na criação de um instrumento facilitador do acesso a trabalhos referentes ao Ensino de Botânica, pois é essencial que sejam divulgados aos professores. Torna-se fundamental que essa produção continue a ser estimulada e que novos/diferentes trabalhos acadêmicos comecem, efetivamente, a provocar um Ensino de Botânica com finalidades renovadoras, como é a proposta do ensino com enfoque CTS para colaborar no processo de Alfabetização Científica, favorecendo a formação de sujeitos ativos na sociedade.

Palavras-chave: Ensino de Botânica, Produções acadêmicas brasileiras, Ensino com enfoque CTS.

\section{Abstract}

The aims of this work were to investigate and analyze how the academic community develops productions regarding differentiated Botanical Teaching, principally with the Science-Technology-Society (STS) approach, and with the scientific literacy of the students. A bibliographical research about academic productions of Botanical Teaching was produced 
in a database in the period between 2012-2017. There is an effort in the productions to improve the Botanical Teaching, principally in the elementary and high schools. However, there are still low of them, especially in terms of STS approach productions. Most of the productions were about high school; productions described as research were the majority and predominated in 2015. In relation to the kind of production, complete articles of indexed journals were the majority. It is interesting that the academic community has invested significantly in the creation of a facilitating document to increase the access of Botanical Teaching works, because the disclosure of this is essential to teachers. It's fundamental that this production continues, and that new/different academic works start, effectively, to promote Botanical Teaching method with renewing finalities, such as the STS approach, in order to collaborate with the Scientific Literacy process, in order to promote the formation of active individuals in society.

Keywords: Botanical Teaching, Brazilian academic productions, STS approach

\section{Introdução}

A maneira como o ensino e a aprendizagem da botânica tem-se configurado nas diferentes etapas e modalidades de ensino, principalmente na Educação Básica brasileira tem sido uma preocupação constante de autores que estudam este assunto. As dificuldades de docentes para tratar de conteúdos de botânica (especialmente na escola), as alternativas criadas para que o estudo dos vegetais torne-se significativo ao estudante e as conexões da Botânica com as diferentes realidades nas quais os educandos estão inseridos são alguns exemplos de problemáticas que se encontram nas produções acadêmicas. Pode-se dizer que isso vem persistindo porque a condução de um ensino da botânica de uma maneira que realmente oportunize o estudante a se utilizar de conhecimentos botânicos para atuação na sociedade em questões que envolvem seu cotidiano ainda passa por barreiras.

A botânica na escola brasileira tem-se resumido à confusa memorização de uma grande quantidade de nomes e de termos botânicos complexos - como, por exemplo, de sistemas classificatórios -, os quais dificilmente atraem os estudantes e, até mesmo, os professores, desmotivando-os para o que poderia contribuir à construção do conhecimento biológico (Santos, 2006). Além disso, a compreensão insuficiente de professores em relação a uma concepção de ensino diferente da tradicional, que os levaria a uma mudança de postura no que se refere às estratégias e aos instrumentos usados nas aulas, pode ser um dos entraves para despertar o interesse dos alunos por botânica, por isso seu ensino tende a não progredir, principalmente, na escola. De acordo Melo et al. (2012):

[...] despertar nos alunos o interesse pela Botânica é um desafio em algumas salas de aula, principalmente se a proposta de ensino for baseada em métodos convencionais restritos aos livros didáticos e aulas expositivas que não atendem a real situação à qual o estudante está inserido. (MELO, et al., 2012, p. 2) 
Esses enfrentamentos precisam ser superados, de modo a alavancar o Ensino de Botânica no Brasil. Para isso, seria necessário colocar a Botânica dentro do contexto social, cultural, político, ambiental em que se encontra o estudante, não apenas para familiarizarse com a linguagem botânica (facilitação da apropriação de conceitos, fenômenos e processos), mas também para que sejam aproveitados os conhecimentos da vida e as demandas que estão em torno do meio (como, as questões de saúde pública e de preservação ambiental). Tais questões estão diretamente ligadas às ações antrópicas no ambiente, portanto se torna importante que sejam levadas para a problematização na escola. Dessa maneira, o sujeito pode ser capaz de se colocar como agente modificador do ambiente e transformador da sociedade, formando opiniões e tomando decisões diante de situações que se depara. O Ensino de Botânica visando a desenvolver a Alfabetização Científica e com enfoque Ciência-Tecnologia-Sociedade (CTS) pode ser um dos caminhos que torne possível a realização de aprendizagens mais significativas e contextualizadas na Educação Básica. Segundo Acevedo (2004), é importante desenvolver uma concepção de ensino de Ciências que permita ao cidadão atuar de maneira democrática nas questões referentes à ciência e à tecnologia na sociedade durante todo o processo que as envolvem, que culmina da tomada de decisões dos sujeitos. Este autor é um dos que defendem o ensino com enfoque CTS como a melhor maneira de se desenvolver, nos estudantes, a Alfabetização Científica. Esta entendida "como a capacidade de ler, compreender e expressar opiniões sobre ciência e tecnologia, mas também participar da cultura científica de maneira que cada cidadão, individual e coletivamente, considerar oportuno" (Krasilchik e Marandino, 2007, p. 30).

Diante disso, as produções acadêmicas que envolvam ensino são importantes e precisam ser desenvolvidas (e, obviamente, suscetíveis de reflexão analítica), pois elas resultam de um conjunto de situações recorrentes que se apresentam na vida diária de docentes e de estudantes. Tais circunstâncias operam consideravelmente na formação dos sujeitos em aprendizagem e na atuação do professor. Em consequência disso, surgem as possibilidades de as produções acadêmicas serem instrumentos indutores de melhoria da qualidade do ensino brasileiro, sobretudo o da botânica. Para Souza e Kindel (2014, p. 45) "muitos pesquisadores têm estudado alternativas que auxiliem os professores a reduzir os desafios encontrados para o Ensino de Botânica", então seria importante e válido investigar como uma concepção de ensino diferente da tradicional tem sido apreciada em produções acadêmicas.

Por isso, buscando averiguar e analisar o quanto a comunidade acadêmica preocupa-se em investir num Ensino de Botânica de melhor qualidade no Brasil, este trabalho, por meio de um levantamento bibliográfico, procurou não só mostrar a produção acadêmica brasileira nesta temática na Educação Básica, mas também examinar como estão configuradas basicamente as estratégias pedagógicas propostas pelas produções para o ensino e a aprendizagem da botânica não serem uma mera memorização de termos, conceitos e definições pelos estudantes. Somam-se a isso, a verificação de se efetivamente as produções têm promovido um Ensino de Botânica baseado numa concepção de ensino que realmente seja contextualizada com o cotidiano dos estudantes e voltada à Alfabetização Científica e ao ensino com enfoque CTS, o que possibilita a formação cidadãos ativos na sociedade. 


\section{Metodologia}

Esta pesquisa é de caráter quali-quantitativo, na qual os dados brutos produzidos foram analisados de maneira subjetiva e avaliados a partir das reflexões das pesquisadoras. Foi conduzida por um estudo de levantamento bibliográfico acerca do Ensino da Botânica no Brasil voltado a uma concepção de ensino diferente da tradicional, como o ensino com enfoque CTS e que busque desenvolver a Alfabetização Científica, em qualquer modalidade de ensino e em relação à formação do professor. É importante destacar que conforme Galvão (2010) em um estudo de levantamento não se pretende apresentar toda a produção existente sobre um conceito genérico, o que até seria inviável, no entanto, busca-se encontrar o que é relevante ao tema de pesquisa para, posteriormente, ser lido e avaliado durante o desenvolvimento do trabalho.

Assim, com este levantamento bibliográfico, desejou-se analisar como o investimento em relação à pesquisa no Ensino de Botânica vem ocorrendo nos últimos anos no Brasil. Por isso, foram definidas para a investigação as produções acadêmicas de trabalhos de conclusão de curso de graduação (TCC), teses e dissertações, artigos completos publicados em eventos e em revistas indexadas.

Para o seu desenvolvimento, acompanharam-se primeiramente as seguintes etapas:

(1) Definição da base de dados disponível no Portal de Periódicos CAPES/MEC: Por meio do endereço deste portal (http://www.periodicos.capes.gov.br), buscou-se a base Google Scholar. Ao entrar na base, o portal direciona-se ao endereço Google Acadêmico (https://scholar.google.com.br)

(2) Escolha do Período de tempo: Uma vez na base estabelecida, na ferramenta chamada de "Pesquisa Avançada", foi possível definir o período da pesquisa, limitado em 2012 até 2017.

(3) Escolha das expressões-chave: ensino de botânica na educação básica, ensino da botânica no ensino fundamental, ensino da botânica no ensino médio, ensino de botânica e ciência-tecnologia-sociedade e ensino de botânica e cts" foram as cinco expressões utilizadas no período estabelecido, sendo pesquisadas como "Encontrar artigos com a frase exata" - uma opção da pesquisa avançada da base. No entanto, para as duas últimas expressões não foram encontrados resultados. Assim, na tentativa de ampliá-los, foi usada a expressão propostas pedagógicas de botânica na escola na opção de ferramenta de pesquisa "Encontrar artigos com todas as palavras".

(4) Seleção das produções encontradas para a produção dos dados: os trabalhos relevantes ao assunto do levantamento, especialmente, os que apresentavam propostas alternativas e diferenciadas, para que o ensino de botânica se torne significativo ao estudante e ao docente, contribuindo para a formação deles, foram selecionados. Os demais foram ignorados.

A partir disso, por meio da leitura e da análise dos títulos, dos resumos e, se necessário, das demais partes dos trabalhos selecionados, estes, então, foram divididos em produções de pesquisa, de relatos de experiência e de extensão e classificados conforme os tipos de produções acadêmicas: (a) trabalhos de conclusão de curso de graduação (TCC), (b) teses e dissertações, (c) artigos completos publicados em eventos e 
(d) artigos de revistas indexadas. Posteriormente, foram classificados de acordo com a identificação a seguir:

(1) EF - Produções voltadas ao Ensino de Botânica relacionadas ao Ensino Fundamental.

(2) EM - Produções voltadas ao Ensino de Botânica relacionadas ao Ensino Médio.

(3) ES - Produções voltadas ao Ensino de Botânica relacionadas ao Ensino Superior.

(4) EJA - Produções voltadas ao Ensino de Botânica relacionadas a Educação de Jovens e Adultos.

(5) FP - Produções voltadas ao Ensino de Botânica direcionadas à formação do professor.

(6) Ml - Produções voltadas ao Ensino de Botânica que estão relacionadas a mais de uma etapa ou modalidade de ensino e à formação do professor.

(7) NI - Produções voltadas ao Ensino de Botânica em que não foi possível a identificação nos critérios anteriores.

Subsequentemente, foi examinado e apresentado, apontando, de forma geral, sobre o que o material propõe. Além disso, da mesma maneira, buscou-se investigar nos trabalhos selecionados a existência de produções acadêmicas relacionadas à concepção de ensino com enfoque CTS e à Alfabetização Científica.

\section{Resultados}

Neste levantamento bibliográfico, verificou-se primeiramente que a maior parte das produções acadêmicas a respeito da temática em estudo concentrou-se no Ensino Médio no que se refere à etapa de ensino. Ainda se observou que os trabalhos de Pesquisa foram os que mais apareceram e predominaram no ano de 2015. Em relação ao tipo de produção, os artigos completos publicados em revistas indexadas foram a maioria. Além disso, foi possível verificar - por meio da análise do material - que a maioria dos trabalhos, quando pretendiam tornar a botânica significativa ao estudante e, até mesmo, ao docente, acabavam abordando fortemente a temática das plantas medicinais em atividades práticas na tentativa de contextualizar conteúdos botânicos com a vida dos educandos. Finalmente, trabalhos baseados no ensino com enfoque CTS foram encontrados, embora muito poucos. Quanto à Alfabetização Científica o mesmo ocorre.

\section{Apresentação dos dados brutos obtidos a partir do levantamento bibliográfico}

Foi possível verificar conforme Tabelas 1 a 3 que, em geral, a maior parte das produções acadêmicas investigadas estão voltadas para o Ensino Médio (35), em seguida, vêm as do Ensino Fundamental (30). Além disso, as produções em Pesquisa são maioria (71) em comparação as de Relatos de Experiência e de Extensão (25 e 3, respectivamente), mesmo que se excluam os dados obtidos das teses e dissertações. Os artigos publicados em revistas indexadas também são maioria em relação às demais produções (Tab. 1, 2 e 3). 
Tabela 1: Produções acadêmicas de Pesquisa.

\begin{tabular}{|l|c|c|c|c|c|c|c|c|}
\hline & EF & EM & ES & EJA & FP & MI & NI & Total \\
\hline Teses e Dissertações & 3 & 2 & 0 & 0 & 0 & 1 & 0 & 6 \\
\hline TCC de Graduação & 2 & 6 & 0 & 0 & 0 & 7 & 1 & 16 \\
\hline Artigos em Eventos & 6 & 5 & 1 & 1 & 3 & 2 & 1 & 19 \\
\hline Artigos em revistas indexadas & 13 & 8 & 1 & 2 & 2 & 3 & 1 & 30 \\
\hline Total & 24 & 21 & 2 & 3 & 5 & 13 & 3 & 71 \\
\hline
\end{tabular}

Tabela 2: Produções acadêmicas de Relatos de Experiência.

\begin{tabular}{|l|c|c|c|c|c|c|c|c|}
\hline & EF & EM & ES & EJA & FP & MI & NI & Total \\
\hline Artigos em Eventos & 2 & 9 & 1 & 1 & 0 & 2 & 2 & 17 \\
\hline Artigos em revistas indexadas & 3 & 3 & 1 & 1 & 0 & 0 & 0 & 8 \\
\hline Total & 5 & 12 & 2 & 2 & 0 & 2 & 2 & 25 \\
\hline
\end{tabular}

Tabela 3: Produções acadêmicas de Extensão.

\begin{tabular}{|l|c|c|c|c|c|c|c|c|}
\hline & EF & EM & ES & EJA & FP & MI & NI & Total \\
\hline Artigos em Eventos & 0 & 1 & 0 & 0 & 0 & 0 & 0 & 1 \\
\hline Artigos em revistas indexadas & 1 & 1 & 0 & 0 & 0 & 0 & 0 & 2 \\
\hline Total & 1 & 2 & 0 & 0 & 0 & 0 & 0 & 3 \\
\hline
\end{tabular}

Foi possível notar que a maior parte da produção acadêmica ocorreu no ano 2014 conforme se observa nas Figuras 1 e 2, totalizando 22 trabalhos, embora não tenha sido encontrada a produção de Extensão naquele ano (Tabela 4). De acordo com a Tabela 4 observa-se que as produções de Extensão apenas foram encontradas no ano de 2016. Além disso, a produção em Pesquisa de 2012 até 2015 aumenta ligeiramente, mas diminui em seguida. Em 2015, esta produção apresenta 16 trabalhos, no entanto teses e dissertações não foram encontradas neste ano de maior produção em pesquisa (Figura 1).

Há, portanto, uma importante oscilação na produção acadêmica dos diferentes tipos de publicação no período investigado de acordo com as Figuras 1 e 2 e Tabela 4 - fato que merece ser analisado e discutido. 


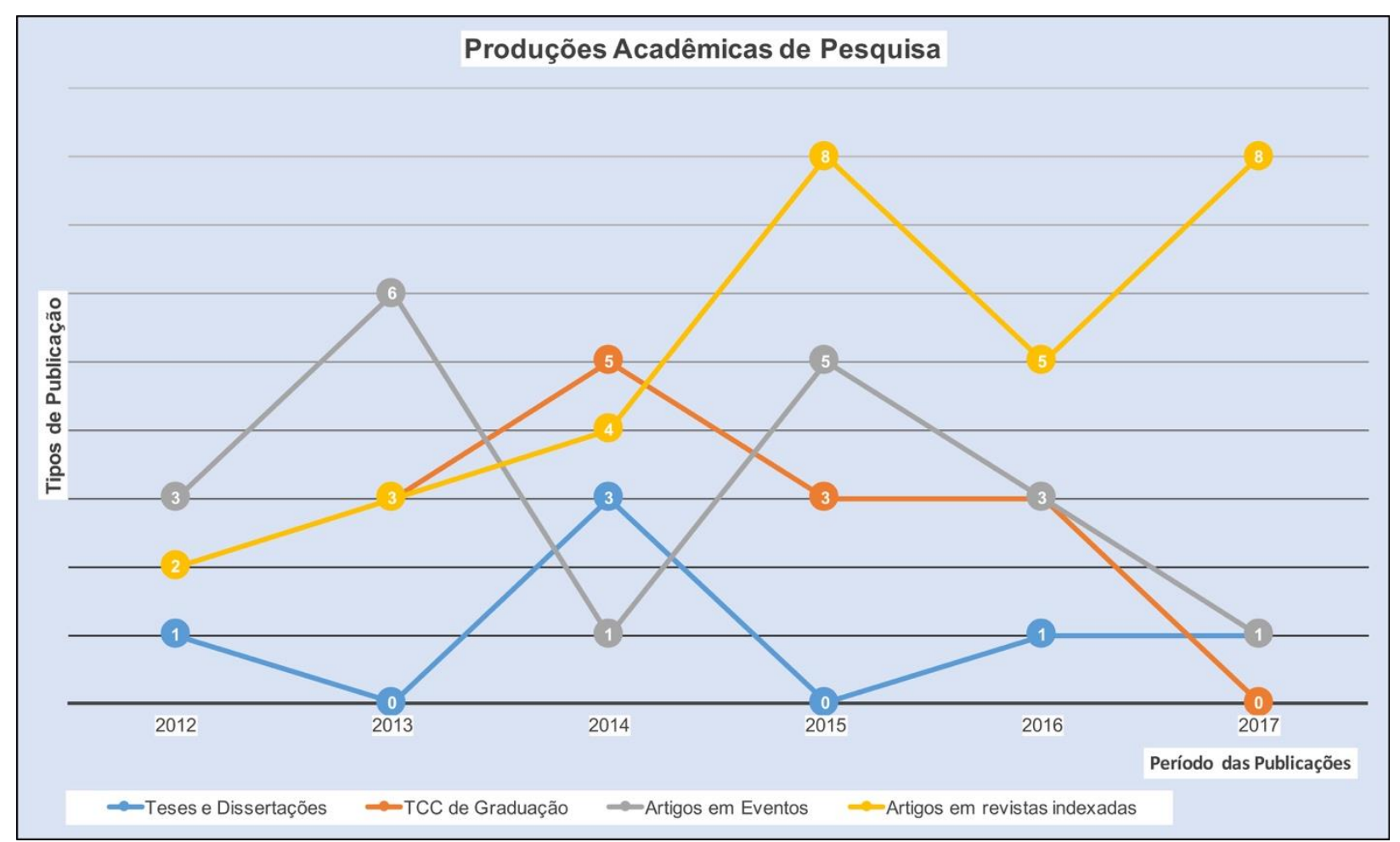

Figura 1 - Produções de Pesquisa entre 2012 - 2017.



Figura 2 - Produções de Relatos de Experiência entre 2012 - 2017. 
Tabela 4: Produção de Extensão entre 2012 - 2017.

\begin{tabular}{|l|c|c|c|c|c|c|c|}
\hline & 2012 & 2013 & 2014 & 2015 & 2016 & 2017 & Total \\
\hline Artigos em Eventos & 0 & 0 & 0 & 0 & 1 & 0 & 1 \\
\hline $\begin{array}{l}\text { Artigos em revistas } \\
\text { indexadas }\end{array}$ & 0 & 0 & 0 & 0 & 2 & 0 & 2 \\
\hline Total & 0 & 0 & 0 & 0 & 3 & 0 & 3 \\
\hline
\end{tabular}

\section{Exemplificando o foco das produções acadêmicas de Ensino de Botânica}

Como as produções acadêmicas examinadas manifestaram propostas diferenciadas para o ensino e a aprendizagem da botânica, torna-se fundamental apresentar uma visão geral de quais assuntos são abordados nos trabalhos. Por essa razão, a seguir, de forma concisa, serão apresentados exemplos contidos no material pesquisados, acerca de algumas temáticas, abordagens e enfoques, de acordo com as classificações adotadas conforme as Tabelas 1, 2 e 3 . Os trabalhos que foram considerados embasados na concepção de ensino com enfoque CTS serão destacados após esta caracterização, na próxima seção.

\section{Ensino Fundamental}

Nesta etapa de escolarização foram encontrados trabalhos que tratavam da aplicação e análise de jogo didático e uso de plantas medicinais, que foram temáticas de pesquisa de dissertação de mestrado. Já algumas pesquisas em artigos de periódicos foram caracterizadas por aspectos relacionados à avaliação do conteúdo de instrumentos pedagógicos (ex. livro didático), ao desenvolvimento atividades práticas e à investigação sobre o porquê de os estudantes apresentarem muitas dificuldades em relação ao estudo vegetais, criando alternativas para o desenvolvimento da Alfabetização Científica dos estudantes. Em pesquisas publicadas em artigos de eventos, em relatos de experiência e também em produção de extensão foram observados também trabalhos relacionados ao desenvolvimento de atividades diferenciadas (em espaço formal e não-formal), como, por exemplo, criação de horta, observação de jardins e participação em oficinas teóricas e práticas, utilizando principalmente plantas medicinais conhecidas dos estudantes. Esses trabalhos tinham como objetivo principal a identificação de plantas, a integração e a sensibilização dos estudantes por estes seres vivos.

\section{Ensino Médio}

Nos trabalhos relacionados ao Ensino Médio, houve alguns classificados em produções de Pesquisa, de Relatos de Experiência e de Extensão, assim como ocorreu na produção do Ensino Fundamental. Atividades práticas para que estudantes percebessem que as plantas também passam por processos fisiológicos como os seres humanos e análise de livros didáticos de diferentes tempos históricos sobre conteúdo de botânica foram abordagens encontradas nas pesquisas de dissertações de Mestrado. Já o uso e análise da temática botânica (ex. plantas medicinais e plantas tóxicas) em sequências didáticas 
com atividades diferenciadas (ex. desenvolvimento de aulas teóricas e práticas em espaços formais e não-formais) e utilização e avaliação de recursos pedagógicos sobre temáticas de botânica (ex. livros didáticos, jogos, vídeos e animações) são alguns exemplos de propostas pedagógicas observadas em pesquisas e relatos de experiência.

\section{Ensino Superior}

No Ensino Superior foram encontradas produções acadêmicas, as quais foram classificadas em pesquisas (2, sendo 1 artigo de revista e 1 de evento) e relatos de experiência (2, sendo 1 artigo de revista e 1 de evento). Há uma pesquisa (artigo revista) que procura entender como alunos universitários acreditam que se configura o ensino da botânica e como ele deveria ser. Além disso, há um relato de experiência (artigo de evento) que trabalha com a temática de reprodução das plantas a partir do estímulo cognitivo do estudante de graduação, propondo atividades diferenciadas como o teatro em sala de aula.

\section{Educação de Jovens e Adultos}

Para Educação de Jovens e Adultos foram encontradas produções acadêmicas classificadas em pesquisa e em relatos de experiência. Análise dos conhecimentos prévios dos estudantes acerca de conceitos botânicos variados, como, por exemplo, de plantas medicinais e o desenvolvimento de aulas de campo constituíram os trabalhos de pesquisa, sendo que os dois primeiros estão classificados em artigos de revistas e o último em artigo de evento. Já trabalhos que envolveram o desenvolvimento de atividades experimentais ( $p$. ex. práticas em laboratório escolar) também eram relacionados às plantas medicinais e integraram os relatos de experiência, bem como a aplicação de jogo didático.

\section{Formação de Professores}

Nos trabalhos relacionados à formação de professores (inicial e continuada) foram encontrados alguns aspectos que serviram de base para pesquisas acadêmicas nesta temática. Um deles (em que se encontrou um trabalho classificado como artigo de revista) é centrado no quanto de conhecimento professores da Educação Básica apresentam a respeito de uma temática (p. ex. plantas medicinais) sobre botânica. $O$ outro se preocupa nas dificuldades encontradas por professores da Educação Básica em trabalhar com os estudantes os conteúdos de botânica, sendo que neste aspecto foram encontrados quatro trabalhos, em que três deles foram classificados em artigo de evento e um em artigo de revista.

\section{Mista}

Foram encontradas produções de pesquisa e relatos de experiência nesta classificação. São alguns dos exemplos dos enfoques observados em trabalhos enquadrados aqui aspectos referentes a formação do professor e estudantes, especialmente da Educação Básica, ao mesmo tempo análises de uso de instrumentos ( $i$. $g$. livro didático em pesquisa em artigo de evento) ou de criação de recursos pedagógicos (i. g. dicionário botânico para alunos surdos em dissertação de mestrado, modelo em três dimensões de plantas para estudantes com deficiência visual em TCC de graduação e jogos em pesquisa em artigo de evento), avaliações de sequências didáticas diversificadas, 
apresentações de propostas alternativas e diversificadas dentro e fora da sala de aula (em pesquisas de TCC de graduação e artigos de revistas) - todos relacionados à Botânica de alguma forma - poderiam ser assuntos que se inter-relacionavam.

\section{Não identificada}

Novamente a temática das plantas medicinais apareceu nas produções acadêmicas de pesquisa como estratégia para se aproximar das vivências dos estudantes, auxiliando na educação ambiental (sendo este um trabalho de conclusão de graduação) e, até mesmo, no reconhecimento delas por alunos com deficiência visual (sendo este um artigo de revista). Há também pesquisa (artigo de evento) à procura de como vem se caracterizando o ensino da botânica, ao se atentar, justamente, para as pretensões de produções acadêmicas. Em relatos de experiência objetivam a facilitação da apropriação de conceitos, quando são propostas atividades com plantas que são utilizadas na vida diária dos alunos, sendo que os focos observados foram o desenvolvimento de sequências didáticas sobre botânica com indígenas e os desafios para a criação de uma horta em uma escola.

\section{Enfoque CTS no Ensino de Botânica}

É importante destacar aqui os tipos de produções acadêmicas que se consideram embasadas no ensino CTS. Foram observados quatro trabalhos enquadrados em produção de pesquisa, sendo um deles um em artigo de revista indexada e voltado para o Ensino Fundamental, outros dois artigos de eventos (um voltado para o Ensino Médio e o outro para o Ensino Superior) e uma dissertação de mestrado voltada ao Ensino Fundamental. Os trabalhos para o Ensino Fundamental focam no desenvolvimento de sequências didáticas baseadas na concepção CTS ou CTSA (Ciência-Tecnologia-SociedadeAmbiente) para abordar temáticas ou conceitos botânicos. Para o Ensino Médio ocorre a avaliação de uma sequência didática proposta pelo docente sob o enfoque CTS. Já no Ensino Superior, há um trabalho que aborda conteúdos botânicos pelo docente de forma tradicional (ex. exposição de conteúdos botânicos) e os estudantes devem apresentar os assuntos a partir do enfoque CTS. Este trabalho também se fundamenta em referenciais que visam à promoção da Alfabetização Científica dos estudantes. Além deste, existe um artigo de revista (relato de experiência), o qual parece, a partir de sua fundamentação teórica, ser baseado no enfoque CTS; este trabalho propõe atividades diferenciadas como criação de site e jogos interativos utilizando a temática das plantas medicinais que poderiam ser usados na Educação Básica.

\section{Discussões}

Percebe-se, por meio deste trabalho de levantamento, que há um incentivo à pesquisa no Ensino de Botânica, sobretudo na Educação Básica, no que se refere à fuga de um ensino tradicional, meramente voltado à memorização de conteúdo. Isso é evidenciado nas Tabelas 1, 2 e 3, cujos dados revelaram que a maior preocupação em relação ao Ensino de Botânica está voltada à Educação Básica, especialmente, ao Ensino Médio (etapa que apresenta maior quantidade de trabalhos). Entretanto, esse estímulo ainda é tímido e merece atenção caso seja almejado um Ensino de Botânica que realmente faça sentido à aprendizagem dos estudantes. Este fato corrobora com Silva, Cavallet e 
Alquini (2005) de que é escassa a produção de publicações referentes à melhoria do Ensino de Botânica no Brasil e esta condição vem se perpetuando até os dias atuais como se pôde constatar neste levantamento.

Nitidamente, segundo a breve exemplificação dos focos dos trabalhos averiguados, observa-se que as produções (em sua maioria) preocupam-se em investigar o Ensino de Botânica, assegurando que o estudo das plantas deveria ser aproximado ao cotidiano dos estudantes (contextualizado), mas isso não demonstra uma modificação expressiva necessária à melhoria do Ensino de Botânica, especialmente na Educação Básica. Ocorrem, na maioria dos materiais investigados, produções que tentam contextualizar a botânica à vida do estudante, como, por exemplo, quando se utiliza a temática das plantas medicinais por meio de atividades e recursos diversificados (p. ex. criação de hortas e jardins didáticos, aplicação de jogos e aulas práticas em laboratórios), a fim de introduzir conceitos botânicos baseadas em percepções de ensino que visam à aprendizagem mais significativa.

Na verdade, o que se vê - nesses trabalhos - é que o desenvolvimento de atividades e recursos pedagógicos diferenciados tem sido entendido como a melhor forma de se obter mais dinamismo durante as aulas, favorecendo, assim, a compreensão dos conteúdos botânicos pelos estudantes. Para Silva, Cavallet e Alquini (2006), professores estão preocupados em aprimorar as metodologias de área de ensino, neste caso, da Botânica e recursos didáticos, e não nas reais condições do ensino que influenciam na formação emancipatória do estudante. De fato, parece promissor o professor desenvolver tais propostas, pois ele tende a se desvencilhar de uma percepção tradicional de ensino (condicionada à reprodução de conteúdo), colaborando não só para que o estudante consiga sensibilizar-se com as plantas, como também para que o educando se interesse pelo estudo dos vegetais e por sua preservação no ambiente. Não significa, porém, que esteja verdadeiramente contextualizando criticamente a Botânica na prática social, ou seja, oferecendo ao estudante a oportunidade de exercer sua cidadania de forma funcional, participativa e responsável. Considera-se "contextualizar" aqui conforme Silva (2007, p. 244) entende: "... significa que o processo ensino-aprendizagem deve partir da realidade concreta (prática social) historicamente determinada, o que significa possibilitar a articulação dos conteúdos com a totalidade". Em outras palavras, a contextualização da botânica implica problematizar a prática social, ou seja, envolve a utilização das diferentes realidades (social, política, cultural, econômica e ambiental) local e global nas quais se insere o estudante para a sua formação integral e crítica, a fim de que ele possa transformar (ou não) a sociedade (Figueiredo, Coutinho e Amaral, 2012). Segundo Chassot (2003), quando se refere ao ensino de Química, o ensino nem transforma a realidade nem mesmo educa para a cidadania quando os conteúdos se resumem a símbolos, cálculos e conceitos desconectados com a realidade.

O ensino de Ciências, em extensão o de Botânica, respaldado no enfoque CTS pode ser uma maneira interessante de contextualizar a botânica no dia a dia do estudante. Para Figueiredo, Coutinho e Amaral (2012), os professores de Ciências, Biologia e Botânica devem praticar uma abordagem diferente da tradicional: devem trabalhar sob um enfoque de ensino que demonstre que o conhecimento científico e tecnológico resulta de construções humanas dentro de um contexto histórico e social, isto é, a CTS, a qual busca 
uma educação para a cidadania, em que o conhecimento científico deve-se relacionar com a realidade do aluno. Segundo Santos (2007), a CTS, na Educação Básica, tem por objetivo promover a educação científica e tecnológica dos educandos para que possam tomar decisões e buscar soluções referentes a questões de ciência, tecnologia na sociedade. Para isso, o docente precisaria ter a clara consciência e compreensão dessa concepção de ensino. Evidentemente, que não deverá ignorar a proposição de atividades diversificadas com temáticas do dia a dia e recursos didáticos aprimorados que possibilitam a valorização das plantas, ao contrário, isso é (sempre) vantajoso e o ensino com enfoque CTS exige do professor isso. Segundo Kindel (2012), ao apresentar o que denomina de "currículo para a vida", cuja criatividade é um dos princípios norteadores, defende que o professor amplie seus métodos de ensino, buscando novas e diferentes fontes para desenvolver trabalhos com os estudantes, como, por exemplo, jornais, revistas vídeos (isto é, ir além da reprodução do conteúdo), além de estimular a interpretação e produção de diversos tipos de textos (como música, charge e história em quadrinhos). Essa autora também defende a ludicidade como sendo fundamental neste currículo, e não complementar ao ensino, visto que motiva a aprendizagem; assim, deve ser sempre estimulada.

Entretanto, o ensino com enfoque CTS também alerta ao docente de que elaborar um planejamento escolar com diferentes métodos e atividades não deve ser entendido como facilitação da assimilação de conteúdos pelos estudantes, a fim de melhorar o ensino e a aprendizagem, particularmente da botânica. As propostas educativas de acordo com a CTS, segundo Acevedo (2004), para que possa ocorrer a promoção de um ensino de Ciências com objetivos mais amplos, devem, por exemplo: incluir sua dimensão social; usar a ciência e tecnologia para propósitos sociais e ação cívica; considerar o papel humanístico, a ética, os valores da ciência e tecnologia; abordar conteúdos para a vida pessoal e social das pessoas para a resolução de alguns problemas referentes a ciência e a tecnologia.

É preciso a reflexão para a definição dos objetivos do Ensino de Ciências, que congregaria o da Botânica, que se deseja alcançar no Brasil atualmente. Desse modo, os currículos escolares voltados à concepção de ensino com enfoque CTS pode ser, portanto, uma direção a ser seguida. Para isso, também é necessária a formação continuada do professor, a fim de que estratégias pedagógicas obsoletas sejam abandonadas em favor da promoção de um ensino que favoreça a Alfabetização Científica do estudante. Neste momento, manifesta-se a real relevância de o professor promover atividades diferenciadas tematizadas e interdisciplinares em conexão com meio em que se que encontra os sujeitos em aprendizagem, pois o ensino CTS, segundo Teixeira (2003, p. 185), "advoga sobre a necessidade de múltiplas estratégias didáticas".

Contudo, como foi possível constatar, mesmo que ocorra um incentivo na produção acadêmica no que refere ao Ensino de Botânica, seja na Educação Básica, seja no Ensino Superior, seja, até mesmo, na formação docente, o investimento em trabalhos que abordem o ensino CTS e a Alfabetização Científica no Ensino de Botânica parecem ser escassos, pois conforme os dados obtidos encontraram-se poucas pesquisas referentes a essa temática. Com este panorama que se apresenta, dificilmente teremos grande influência da produção acadêmica de diferentes naturezas na atuação docente que possibilite o desprendimento de um modelo de ensino de Botânica que vem sendo sustentado por estratégias pedagógicas essencialmente conceituais, focadas na linguagem científica. $\mathrm{Na}$ 
verdade, de acordo com a análise dos trabalhos em relação a formação do professor, não foram encontradas produções que fizessem relação real entre CTS, Ensino de Botânica e formação do docente.

Assim, Ensino da Botânica precisa, sem dúvida, de transformação. Já é consenso entre os que se dedicam ao estudo desta temática conforme revelaram as produções acadêmicas examinadas acerca dos constantes desafios e limitações que a botânica enfrenta no seu ensino, tanto para o estudante, quanto para o docente. Dessa maneira, reitera-se que o Ensino de Botânica precisa-se voltar à emancipação do educando e professor tem papel fundamental nesse processo. Para Silva (2007, p. 246):

[...] o saber escolar não pode ter como único componente o conhecimento científico, e, além disso, se esse conhecimento é fragmentado, o saber escolar pretende ser justamente o contrário: a construção articulada com os dados do mundo, a fim de torná-los um todo coerente, compreensível às crianças, aos jovens e aos adultos. [...] O papel de professor que repassa/reproduz o conhecimento científico para os alunos sem possibilitar uma aprendizagem contextualizada e inviabilizando que o aluno seja sujeito da aprendizagem não é só reflexo do sistema universitário, mas também de uma postura/decisão pessoal do professor. (SILVA, 2007, p. 246).

As inconstâncias presentes no período e nos meios de publicação revelaram-se também como impedimentos para que o Ensino de Botânica progrida na educação brasileira. No que se refere à relação do período (2012-2017) das produções acadêmicas encontradas, mesmo que a maior produção em Pesquisa tenha acontecido no ano de 2015 (Figura 1) e que no ano de 2014 tenha ocorrido a maior de produção dos diferentes tipos de publicação investigados (Figuras 1 e 2; Tabela 4), os dados revelam insuficiência de trabalhos, que parecem não aumentar ao passar dos anos. Ao contrário, na produção de Pesquisa, o número aumenta entre 2012 e 2015, mas logo volta a diminuir. Para os Relatos de Experiência, acontece algo parecido: entre 2012-2014 há aumento na produção, em seguida uma queda (2015) e novamente aumenta em 2016 e depois cai de novo. E finalmente, para a produção de Extensão só há produção em 2016, permanecendo esta, então, estagnada (Tabela 4). Esses resultados, portanto, não necessariamente demonstram que o Ensino da Botânica estaria ficando melhor qualificado no Brasil. Porém, este contexto de falta de interesse e investimento em pesquisas que busquem qualificar 0 ensino e a aprendizagem sobre botânica podem indicar mais um entrave para qualificar mais a abordagem desta temática, demonstrando que a produção acadêmica precisa ser ampliada e enriquecida.

Houve dificuldades para localizar também essas produções, pois elas encontravam-se pulverizadas em diferentes meios de publicação (como em diferentes periódicos), principalmente as relacionadas ao ensino com enfoque CTS, mesmo que se tenha ampliado com nova expressão-chave a consulta na base de busca (Google Acadêmico), a qual é bastante simples de manejar. Isso também pode dificultar ao docente que deseja buscar - em algum momento - atualização/formação em relação à temática, representando mais um obstáculo para favorecer a renovação na forma de ensinar Botânica. Segundo Silva, Cavallet e Alquini (2005) periódicos de áreas específicas da Botânica dominam as publicações neste campo. Ou seja, os autores estão falando dos que não se relacionam ao ensino e à educação. Dessa maneira, segundo esses autores, torna- 
se impossível a produção relacionada ao ensino e, em relação às produções voltadas à educação, afirmam que estas abordam questões sobre didáticas, relacionadas às ciências em geral e não à Botânica em especial.

Assim, seria interessante que a comunidade acadêmica investisse na criação de um instrumento facilitador do acesso a trabalhos referentes ao Ensino de Botânica como, por exemplo, um periódico, isto é, uma revista indexada que concentrasse produções desenvolvidas, tanto nacional como internacionalmente. Essa iniciativa seria uma forma de dar a devida visibilidade e a valorizar esta temática e poderia encorajar os professores a tratarem a botânica de forma mais qualificada. Para isso, é essencial que também sejam viabilizadas ações de divulgação deste periódico, principalmente aos docentes da Educação Básica, de modo que as produções acadêmicas não fiquem em torno apenas dos próprios pesquisadores.

\section{Conclusões}

As produções acadêmicas de ensino comumente representam aquilo que é constantemente anunciado na prática docente diária. Conforme evidenciam as que foram investigadas, em geral, mostraram, discutiram e avaliaram, majoritariamente, propostas pedagógicas (e. g. atividades práticas e de campo) e instrumentos didáticos (e. g. livros didáticos) porque existe uma preocupação, mesmo que sutil, na melhoria da qualidade do Ensino de Botânica. Entretanto, o ensino e a aprendizagem de botânica vão muito além da simples ideia de que a facilitação da assimilação de conceitos por parte dos estudantes mediante a proposição de atividades diversificadas e o uso de métodos e de recursos aprimorados, considerados dinamizadores das aulas sobre o estudo dos vegetais, seria a melhor forma de contextualizar a botânica no cotidiano do estudante. Verdadeiramente, essa situação precisa é ser superada, demonstrando a necessidade de entendimento real (principalmente dos docentes) de que os estudantes precisam é formação para sua emancipação, ou seja, para atuar crítica e conscientemente naquilo que envolve a sua vida social, por meio da formação de sua Alfabetização Científica.

Este trabalho também apontou a carência em produções em Ensino de Botânica já denunciada por outros autores, pois existe uma tendência em valorizar a produção em áreas específicas da Botânica e não em ensino, mostrando que esse quadro precisa urgentemente de mudança, para que o Ensino de Botânica possa ter condições de vencer suas limitações. Por essa razão, o incentivo à produção em pesquisa em Ensino de Botânica precisa ser ampliado, sendo essencial que as produções sejam divulgadas aos professores, principalmente de maneira descomplicada. Por isso, sugere-se que seja estimulado o desenvolvimento de um periódico de produções de Ensino de Botânica no País pela comunidade acadêmica. Além disso, é necessário que sejam elaborados trabalhos acadêmicos os quais comecem - de fato - a provocar um Ensino de Botânica com finalidades renovadoras, como é o ensino com enfoque CTS, a fim de que colabore na formação de sujeitos ativos na sociedade. 


\section{Referências}

ACEVEDO. J. A. Reflexiones sobre las finalidades de la enseñanza de las ciencias: educación científica para la ciudadanía. Revista Eureka sobre Enseñanza y Divulgación de las Ciencias, v. $1, \quad$ n. 1, p. 3-15, 2004. Disponível em: http://www.redalyc.org/articulo.oa?id=92010102. Acesso em: 19 jun. 2018.

CHASSOT, A. I. Alfabetização científica: questões e desafios para a educação, 3ạ. ed., ljuí: Ed. Unijuí, 2003.

FIGUEIREDO, J. A.; COUTINHO, F. A.; AMARAL, F. C. O ensino de botânica em uma abordagem ciência, tecnologia e sociedade. Em: II SEMINÁRIO HISPANO BRASILEIRO CTS. Anais..., p. 488-498, 2012. Disponível em: http://revistapos.cruzeirodosul.edu.br/index.php/rencima/article/viewFile/420/353. Acesso em: 3 dez. 2017.

GALVÃO, M. C. B. O levantamento bibliográfico e a pesquisa científica. Em: Laércio Joel Franco, Afonso Dinis Costa Passos. (Org.). Fundamentos de epidemiologia, 2ª ed., São Paulo: Manole, p. -, 2010.

KINDEL, E. A. I. A docência em Ciências Naturais: construindo um currículo para o aluno e para a vida. Erechim: Edelbra, 2012.

KRASILCHIK, M., E MARANDINO, M. Ensino de ciências e cidadania, 2ª ed., São Paulo: Moderna, 2007.

MELO, E. A.; ABREU, F. F.; ARAÚJO, M. I. O. A aprendizagem de botânica no ensino fundamental: dificuldades e desafios. Scientia Plena, v. 8, n. 10, p. 1-8, 2012. Disponível em: http://www.scientiaplena.org.br/ojs/index.php/sp/article/viewFile/492/575. Acesso em: 14 dez. 2017.

SANTOS, F. S. A Botânica no Ensino Médio: será que é preciso apenas memorizar nomes de plantas?. Em: SILVA, C. C. (Org.) Estudos de História e Filosofia das Ciências: subsídio para aplicação no Ensino. São Paulo: Livraria da Física, p. 223-243, 2006.

SANTOS, W. L. P. Educação científica na perspectiva de letramento como prática social: funções, princípios e desafios. Revista Brasileira de Educação, v. 12, n. 36, p. 474-492, 2007. Disponível em: http://www.scielo.br/pdf/rbedu/v12n36/a07v1236.pdf. Acesso em: 3 dez. 2017.

SILVA, L. M. Metodologia para o ensino de Botânica: o uso de textos alternativos para identificação de problemas da prática social. Revista Brasileira de Estudos Pedagógicos, Brasília, v. $88, \quad$ n. 219, p. 242-256, 2007. Disponível em: http://rbep.inep.gov.br/index.php/rbep/article/view/746. Acesso em: 19 dez. 2017.

SILVA, L. M.; CAVALLET, V. J.; ALQUINI, Y. Contribuição à reflexão sobre a concepção de Natureza no ensino de Botânica. Revista Brasileira de Estudos Pedagógicos, Brasília, v. $86, \quad$ n. $213 / 214$, p. 110-120, 2005 . Disponível em: http://rbep.inep.gov.br/index.php/rbep/article/view/839. Acesso em: 19 dez. 2017.

SILVA, L. M.; CAVALLET, V. J.; ALQUINI, Y. O professor, o aluno e o conteúdo no ensino de Botânica. Educação, Santa Maria, v. 31, n. 01, p. 67-80, 2006. Disponível em: http://www.redalyc.org/pdf/1171/117117257006.pdf. Acesso em: 19 dez. 2017. 
SOUZA, C. L. P., e KINDEL, E. A. I. (2014). Compartilhando Ações e Práticas Significativas para o Ensino de Botânica na Educação Básica. Experiências em Ensino de Ciências, v. 9, n. $\quad 3, \quad$ p. $\quad 44-58 . \quad$ Disponível em: http://if.ufmt.br/eenci/artigos/Artigo_ID253/v9_n3_a2014.pdf. Acesso em: 19 jun. 2018.

TEIXEIRA, P. M. M. A educação científica sob a perspectiva da pedagogia histórico-crítica e do movimento C.T.S. no ensino de ciências. Ciência \& Educação, v. 9, n. 2, p. 177-190, 2003. Disponível em: http://www.scielo.br/pdf/ciedu/v9n2/03.pdf. Acesso em: 3 dez. 2017.

Submissão: $15 / 01 / 2018$

Aceite: 19/06/2018 